\title{
A Model of Chronic Pain in the Rat: Functional Correlates of Alterations in the Activity of Opioid Systems
}

\author{
M. J. Millan, ${ }^{1}$ A. Czkonkowski, ${ }^{1}$ C. W. T. Pilcher, ${ }^{1}$ O. F. X. Almeida, ${ }^{1}$ M. H. Millan, ${ }^{1}$ F. C. Colpaert, ${ }^{2}$ and A. Herz ${ }^{1}$ \\ 'Department of Neuropharmacology, Max-Planck-Institut für Psychiatrie, D-8033 Planegg-Martinsried, F.R.G., and ${ }^{2} J a n s s e n$ \\ Pharmaceutica Research Laboratories, B-2340 Beerse, Belgium
}

Intradermal inoculation of rats at the tail base with Mycobacterium butyricum led to the gradual development of an arthritic swelling of the limbs which peaked at 3 weeks and subsided thereafter. Arthritic rats displayed a loss of body weight, hypophagia, and hypodipsia in addition to a disruption of the diurnal rhythms of ingestive behavior and of core temperature. The activity of adenohypophyseal $\beta$-endorphin- ( $\beta$-EP) secreting corticotrophs, in contrast to prolactin(PRL) secreting lactotrophs, was increased in arthritic rats. Indeed, hypertrophy of the adrenal glands was seen. Arthritic rats also showed an elevation in spinal cord levels of immunoreactive dynorphin (DYN), an endogenous ligand of the $k$-opioid receptor.

The paws and tail of arthritic rats showed lower thresholds in response to noxious pressure (hyperalgesia), higher thresholds in response to noxious heat (hypoalgesia), and no change in their response to noxious electrical stimulation. Neither naloxone nor $\mid \mathrm{Cl}-154,129$ (a preferential $\delta$-receptor antagonist) modified the responses of the paw or tail to pressure. However, MR 2266 (an antagonist with higher activity at $k$-receptors) decreased thresholds to pressure in arthritic, but not control, rats; that is, it potentiated the hyperalgesia. This action was stereospecific. None of the antagonists modified the response to heat. MR 2266 did not affect the response to pressure in rats with acute inflammation produced by yeast. Thus, the potentiation of pressure hyperalgesia by MR 2266 in chronic arthritic rats is highly selective. Arthritic rats showed a reduced response to the analgesic effect of a $\kappa$-agonist (U-50,488H), whereas the response to a $\mu$-agonist (morphine) was enhanced. These effects were specific to nociception in that their influence upon endocrine secretion (PRL and $\beta$-EP) was otherwise changed. The secretion of $\beta$-EP and PRL was stimulated by

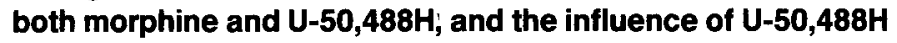
upon the release of $\beta$-EP (from the adenohypophysis) was enhanced in arthritic rats.

\footnotetext{
Received Feb. 25, 1986; revised May 20, 1986; accepted June 19, 1986.

M.J.M. was supported by the Deutsche Forschungsgemeinschaft. A.C. is a visiting scientist at the Department of Pharmacology, Institute of Physiological Sciences, Medical Academy of Warsaw, Poland. C.W.T.P. is a member of the Faculty of Medicine, University of Kuwait, Kuwait. We thank the following for their generous donation of drugs: Endo Laboratories (U.S.), naloxone; Upjohn Company (Kalamazoo, MI), U-50,488H; Imperial Chemical Industries (Macclesfield, UK), ICI-154, 129; and Boehringer (Ingelheim, F.R.G), MR 2266 and MR 2267. Correspondence should be addressed to Dr. Mark J. Millan, Department of Neuropharmacology, Max-Planck-Institut für Psychiatrie, Am Klopferspitz 18a, D-8033 Planegg-Martinsried, Federal Republic of Germany.

Copyright (C) 1987 Society for Neuroscience $0270-6474 / 87 / 010077-11 \$ 02.00 / 0$
}

It is suggested that polyarthritis is a complex condition entailing many changes, both behavioral and endocrinological. Further, arthritic rats cannot simply be described as "hyperalgesic": of critical importance is the nature of the nociceptive stimulus applied. The parallel alterations in spinal cord pools of DYN and $\boldsymbol{k}$-receptors (see also Millan et al., 1986) and the changes in the influence on nociception of $k$-agonists and $k$-antagonists suggest an increased activity of spinal DYN. Thus, spinal $k$-receptors may play a role in the modulation of nociception under chronic pain. Finally, there is a clear distinction between the functional response of $\mu$ - as compared with $\kappa$-receptors to chronic pain in the rat.

Numerous studies have indicted that the functional activity of endogenous opioid systems can be modified by the imposition of acute noxious stimulation (Millan, 1981, 1986; Millan et al., $1981 \mathrm{a}, \mathrm{b}$; Yaksh and Elde, 1981; Watkins and Mayer, 1982; Nyberg et al., 1983; Panerei et al., 1984; Yaksh et al., 1983; Basbaum and Fields, 1984; Terman et al., 1984). More recently, we (and others) have directed our attention towards the comparatively poorly understood problem of the response of endogenous opioid systems to chronic noxious stimulation, a subject of spccial clinical relevance (Ccssclin ct al., 1980, 1984; Guilbaud et al., 1982; Faccini et al., 1984; Iadorola et al., 1985; Millan et al., 1985, 1986a, b).

By means of a variety of biochemical techniques, rats subjected to the chronic pain of polyarthritis were shown to exhibit pronounced selective, reversible, and contrasting alterations in the activity of the CNS and hypophyseal pools of $\beta$-endorphin ( $\beta$-EP), methionine-enkephalin (ME), and dynorphin (DYN) (Millan et al., 1985, 1986a, b). These are major gene products corresponding to each of the 3 known families of opioid peptides-pro-opiomelanocortin, pro-enkephalin A, and pro-enkephalin B (pro-dynorphin), respectively (Höllt, 1983; Millan and Herz, 1985). In addition, differential effects upon the densities of the opioid receptor types $\mu, \delta$, and $\kappa$ were observed (Millan et al., 1986a). Of special interest was the parallel reduction in $\kappa$-receptors and the enhancement of the concentration of immunoreactive (ir) DYN - considered an endogenous ligand of the $\kappa$-receptor (Wüster et al., 19.81; Robson et al., 1983; James et al., 1984)-in thalamus and spinal cord. These structures are of major importance in the processing of noxious information, a function in which opioids may play a role (Hill and Pepper, 1979; Benoist et al., 1983; Basbaum and Fields, 1984; Millan, 1986). In polyarthritic rats, neurons located in these structures have been found to display modified responses to noxious stim- 
uli (Menetrey and Besson, 1982; Gautron and Guilbaud, 1983). Also, a $\kappa$-receptor-mediated action of DYN in the spinal cord has often been suggested as playing a role in antinociceptive mechanisms (Przewlocki et al., 1983; Basbaum and Fields, 1984; Han et al., 1984; Spampinato and Candeletti, 1985; Millan, 1986).

One might anticipate from the above that there would be alterations in the nociceptive thresholds of arthritic rats and that they might respond differently to exogenously applied opioid agonists and antagonists. Indeed, the limited data available indicate that chronic pain may modify the influence of morphine and naloxone upon nociception (Colpaert, 1979; Colpaert et al., 1980; Kayser and Guilbaud, 1981, 1983, 1985; Guilbaud et al., 1982).

In the present study, we undertook a systematic evaluation of the behavioral characteristics of arthritic rats, of their response to various types of noxious stimuli, and of the influence upon this response of opioid agonists and antagonists selective for particular opioid receptor types. In addition, we examined the secretion of $\beta$-EP and prolactin (PRL), 2 pituitary hormones which characteristically respond to acute pain or stress and whose release is modulated by opioids (Millan and Herz, 1985). The data provided a direct counterpart to our biochemical studies (Millan et al., 1986a) in identifying the functional significance of the alterations in activity of endogenous opioid systems observed in animals in chronic pain.

Part of this work has previously appeared in brief form (Millan et al., 1985).

\section{Materials and Methods}

\section{Induction of arthritis}

The procedure employed was identical to that of our previous studies (Millan et al., 1985, 1986a). Male Wistar rats of $\sim 300 \mathrm{gm}$ were inoculated at the tail base with $0.05 \mathrm{ml}$ of either a suspension of killed Mycobacterium butyricum or paraffin oil (vehicle control). They were housed individually, with free access to rat chow and water, in cages with floors lined with sawdust. Room temperature was maintained at $22 \pm 0.5^{\circ} \mathrm{C}$ and $60 \%$ humidity. A $12 \mathrm{hr}$ light-dark cycle was used, with lights being turned on at 7:30 A.M.

Unless otherwise stated, all testing was performed in the light phase and each study employed a separate group of arthritic and control rats. Unless otherwise specified, all testing was done at $21 \mathrm{~d}$, the time of peak arthritis.

\section{Behavioral characteristics of arthritic rats}

Body weight was monitored at weekly intervals just before onset of the dark period.

The diurnal rhythmicity of food intake and water intake was evaluated over a period of $5 \mathrm{~d}$ (days 18-23 postinoculation). The data across the $5 \mathrm{~d}$ period were pooled for analysis. The quantity of food and water (available from leakproof bottles) consumed was determined for both the dark and light phases of the daily cycle. Measurements were made immediately following the end of the respective phases.

On days 20 and 21 , during both the light (10:30 A.M.) and dark (10:30 P.M.) phases, core temperature was evaluated by insertion of a digital thermistoprobe into the rectum to a depth of $5 \mathrm{~cm}$ for $30 \mathrm{sec}$.

\section{Algesiometric tests}

Five tests were used. The time course of arthritis-induced alterations in the nociceptive threshold was monitored by administering the first 4 tests described below at $4 \mathrm{~d}$ intervals; the vocalization test was used only once, at the time of peak arthritis, 3 weeks postinoculation. (At that time, in addition to testing the rats whose time course was being evaluated, we examined naive rats that had not as yet been tested.) On any occasion where more than 1 test was employed, the order was as follows: tail-flick to heat; tail withdrawal to pressurc; paw withdrawal to pressure; paw withdrawal to heat; vocalization to electrical stimulation.

Tail-flick to heat. The latency for removal of the tail from a beam of noxious light focused on its tip was evaluated. The mean of 3 consecutive readings (separated by intervals of $10 \mathrm{sec}$ ) was determined. A cutoff of $10 \mathrm{sec}$ was enforced in order to preclude tissue damage.

Tail withdrawal to pressure. The rat was gently restrained under paper wadding and incremental pressure was applied via an accelerating, blunt, wedge-shaped piston at a point $2 \mathrm{~cm}$ from the tip of the tail; the pressure required to elicit tail withdrawal was detcrmincd. The mcan of 3 consecutive values (separated by intervals of $10 \mathrm{sec}$ ) was determined. There was a cutoff of $400 \mathrm{gm}$.

Paw withdrawal to heat. A large bath of circulating water was thermostatically maintained at $49^{\circ} \mathrm{C}$. The rat was held gently in the hand, and the right hindpaw was dipped below the surface of the water such that the entire foot and tibiotarsal joint were submerged. The rats remained calm, and the latency to withdrawal of the paw was determined. The mean of 3 consecutive values (separated by intervals of $10 \mathrm{sec}$ ) was determined. There was a cutoff time of $8 \mathrm{sec}$.

Paw withdrawal to pressure. The method employed was essentially as described above for the tail, but with application of pressure to the dorsal surface of the right hindpaw. The pressure required for the withdrawal of the paw was measured. The mean of 3 consecutive values (separated by intervals of $10 \mathrm{sec}$ ) was estimated, with a cutoff at 300 gm.

Vocalization to electrical stimulation. Rats were gently restrained under paper wadding, and a moistened bipolar electrode was attached to the middle of the tail. The tail was stimulated with $20 \mathrm{msec}, 50 \mathrm{~Hz}$ square-wave pulses delivered for $1.5 \mathrm{sec}$ in a sequence of currents increasing in voltage. The vocalization threshold, that is, the voltage required to elicit vocalization, was determined.

\section{Influence of opioid antagonists}

Naloxone and ICI-154,129 were dissolved in saline, and MR 2266 and MR 2267 were dissolved in saline acidified with $\mathrm{HCl}$ and adjusted with $\mathrm{NaOH}$ to near-neutrality. All drugs were applied subcutaneously in a volume of $1.0 \mathrm{ml} / \mathrm{kg}$. Naloxone, MR 2266, and MR 2267 were applied at a dose of $5.0 \mathrm{mg} / \mathrm{kg}$ and ICI-154,159 at $30 \mathrm{mg} / \mathrm{kg}$. Baseline thresholds were read; then the rats were injected and returned to their home cages. Fifteen minutes later, the thresholds were reevaluated. These experiments were performed blind: The experimenter injecting the rats and reading the thresholds was unaware of the identity of the solution applied. In one set of experiments, tail heat and tail pressure thresholds were determined and, in an independent experiment, paw pressure and paw heat.

\section{Influence of opioid agonists}

Both morphine and U-50,488 $\mathrm{H}$ were dissolved in saline and injected in a volume of $1.0 \mathrm{ml} / \mathrm{kg}$, s.c.

Baseline thresholds were determined and the rats were injected and returned to their home cages. Thresholds were reevaluated at time intervals as specified in the figures. In periods between measurements, rats were allowed to sit in their home cages.

\section{Influence of MR 2266 upon yeast-induced hyperalgesia in naive rats}

Naive, nonarthritic rats were injected under light ether anesthesia in the plantar surface of the right hindpaw with $100 \mu$ l of a $20 \%$ suspension of yeast in water. This led to rapid swelling and inflammation of the hindpaw within $1 \mathrm{hr}$ postapplication.

Paw pressure thresholds were evaluated immediately prior to injection and $1 \mathrm{hr}$ afterwards. The rats were then injected with saline or MR $2266(5.0 \mathrm{mg} / \mathrm{kg}, 1.0 \mathrm{ml} / \mathrm{kg}$, s.c.). They were returned to their home cages, and, 15 min later, paw pressure thresholds were redetermined.

\section{Influence of morphine and U-50,488H on endocrine secretion: radivimmunoassays}

The rats were injected with saline, morphine $(2.0$ or $4.0 \mathrm{mg} / \mathrm{kg}, 1.0 \mathrm{mV} /$ $\mathrm{kg}$, s.c.), or $U-50,488 \mathrm{H}(10.0 \mathrm{mg} / \mathrm{kg}, 1.0 \mathrm{ml} / \mathrm{kg}$, s.c.) and returned to their home cages; 30 min later they were decapitated and their trunk blood was collected in chilled tubes and centrifuged at $4000 \mathrm{rpm}$ for 10 min. The plasma was removed and frozen on dry ice. The pituitary was 
Table 1. The influence of chronic polyarthritis upon various parameters in the rat

\begin{tabular}{|c|c|c|c|c|c|c|}
\hline & $\begin{array}{l}\text { Hindpaw } \\
\text { wt. } \\
\text { (gm) }\end{array}$ & $\begin{array}{l}\text { Tibiotarsal joint } \\
\text { circumference } \\
\text { (mm) }\end{array}$ & $\begin{array}{l}\text { Front paw wt. } \\
(\mathrm{gm})\end{array}$ & $\begin{array}{l}\text { Adrenal wt. } \\
\text { (mg) }\end{array}$ & $\begin{array}{l}\text { Adrenal wt./body wt. } \\
\text { (mg/100 gm) }\end{array}$ & $\begin{array}{l}\text { Spinal cord: ir DYN } \\
\text { (fmol/ } / \mathrm{mg})\end{array}$ \\
\hline Control & $2.07 \perp 0.04(22)$ & $3.12 \pm 0.06(22)$ & $1.71 \pm 0.07(22)$ & $44.91 \pm 1.87(23)$ & $12.76 \pm 0.53(23)$ & $45.15 \pm 1.89(17)$ \\
\hline Arthritis & $* * * 3.86 \pm 0.09(33)$ & $* * * 4.59 \pm 0.08(33)$ & $* * * 2.56 \pm 0.14(33)$ & $* * 53.93 \pm 1.83(28)$ & $* * * 19.12 \pm 0.65(28)$ & $* * * 96.53 \pm 5.88(11)$ \\
\hline
\end{tabular}

Means $\pm \mathrm{SEM} ; n$ is in parentheses. Significance of arthritic vs control values is indicated by asterisks; ${ }^{* *} p \leq 0.01 ;{ }^{* * *} p \leq 0.001$ (Student's 2 -tailed $t$ test).

rapidly removed and divided into the anterior and neurointermediate (the intermediate lobe plus adhering neural lobe) lobes. The lumbosacral spinal cord was also rapidly removed. These tissues were weighed, incubated in $5 \mathrm{vol} \mathrm{HCl}$ at $97^{\circ} \mathrm{C}$ for $10 \mathrm{~min}$, and frozen on dry ice.

All procedures for tissue preparation and extraction of $\beta$-EP and DYN, for radioimmunoassay as well as characteristics of the antibodies, have been extensively described previously (Höllt et al., 1978; Weber et al., 1982). Briefly, the antibody against $\beta$-EP recognized $\beta$-lipotropin to an equimolar extent but did not significantly bind adrenocorticotropin, alpha-melanocyte-stimulating hormone, DYN, ME, or any other peptides tested. The detection limit was $2 \mathrm{fmol} /$ tube. The antibody to DYN did not significantly bind $\mathrm{DYN}_{\mathrm{t}-8}$, DYN B, leucine-enkephalin, alpha-neo-endorphin, or any other peptides tested. The detection limit was $1 \mathrm{fmol} /$ tube.

PRL was determined by use of a double-antibody radioimmunoassay employing reagents and protocols provided by the NIADDM, Bethesda, MD. Anti-rat PRL serum was used at a final dilution of $1: 16,000$. The detection limit was $\sim 0.1 \mathrm{ng}$ (values are expressed in nanograms per milliliter according to the NIH rat PRL standard, NIH-RP-3).

\section{Statistics}

Student's 2-tailed $t$ test, Wilcoxon's matched-pairs test, Pearson's product-moment correlation, and analysis of variance (ANOVA) were used as appropriate and are indicated below.

\section{Results}

About 10-12 d postinoculation, the rats developed arthritic inflammation and swelling of the limbs and upper tail, which was most pronounced in the hindlimbs. This reached a peak at around 3 weeks and then subsided until, at 10 weeks postinoculation the rats had largely recovered.

As indicted in Table 1, at 3 weeks these arthritic symptoms were reflected in a pronounced increase in the weight of both hindlimbs and forelimbs as well as in the circumference of the tibiotarsal joint. In addition, there was an increase in the weight of the adrenal glands. In confirmation of our previous work (Millan et al., 1986a) there was a marked elevation in the concentration of ir DYN in the lumbosacral spinal cord.

It may be seen from Figure 1 that arthritic rats showed a pronounced reduction in the rate of body weight gain beginning with the onset of symptoms. In parallel with their recovery from arthritis, the rate of weight gain began to increase at a rate which was, in fact, in excess of that shown by control rats over this period (percentage change in body weight from week 5 to 10 as a percentage of body weight at week 5 : $\operatorname{sham}(n=12), 15.01 \pm$ 2.94; arthritic $(n=12), 37.72 \pm 5.94$; mean $\pm \mathrm{SEM}, p \leq 0.001$; Student's 2-tailed $t$ test).

Arthritic rats, at the time of peak arthritis, displayed a reduction in $24 \mathrm{hr}$ daily food and water intake (Fig. 1). This decrease was restricted to the dark phase, and arthritic rats consumed significantly more food than did sham animals during the light phase (Fig. 1). That the diurnal rhythmicity of food a. food intake
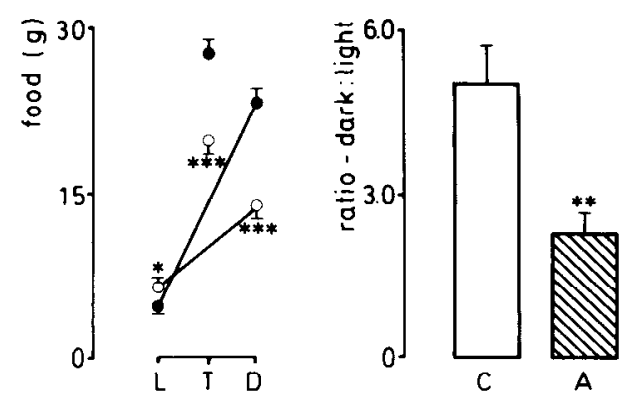

c. body weight

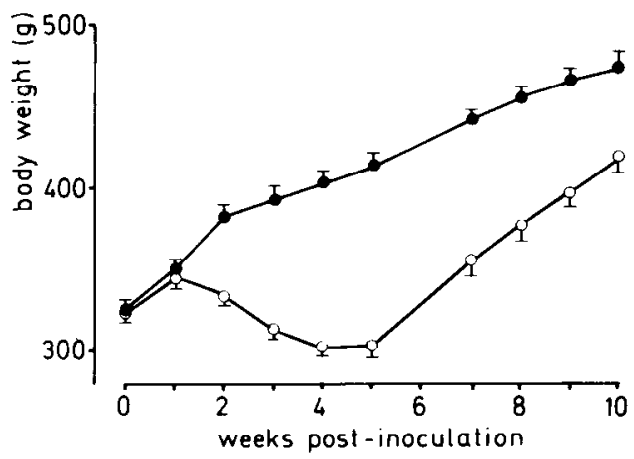

b. water intake

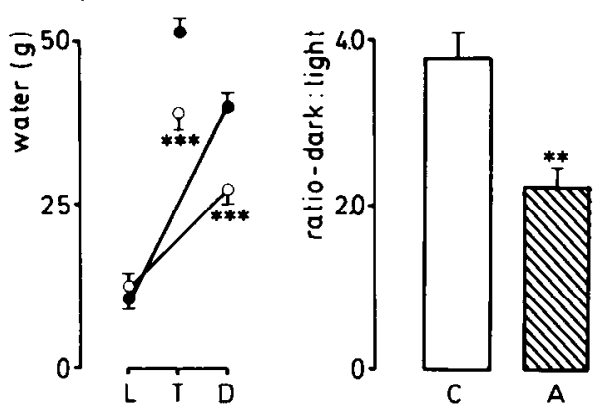

d. core temperature
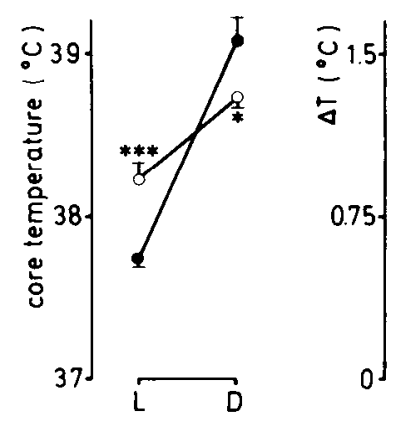

Figure 1. The influence of chronic arthritis in the rat upon $(a)$ food intake, (b) water intake, $(c)$ body weight and $(d)$ core temperature. Closed circles and open circles represent control and arthritic rats, respectively. $a$ and $b, L, D$, and $T$ represent intake for, respectively, light phase, dark phase, and total 24 hr of daily cycle. Columns depict the ratio of dark-phase:light-phase consumption. $C$, Control $(n=12) ; A$, arthritis $(n=12)$. Means \pm SEM. Significance of arthritic vs control values is indicated by asterisks. ${ }^{*} p \leq 0.05 ;{ }^{* *} p \leq$ $0.01 ;{ }^{* * *} p \leq 0.001$ (Student's 2-tailed $t$ test). $c$, Means $\pm \mathrm{SEM}, n=12$ for both groups. From 2 weeks, values in arthritic rats significantly differ from control values $(p<0.01$ at each time point; Student's 2-tailed $t$ test). $d$, Abbreviations and numbers of rats as specified above for panels $a$ and $h . \Delta T$ $\left({ }^{\circ} \mathrm{C}\right)$ refers to the difference between light-phase $(L)$ and dark-phase $(D)$ core temperatures. Means \pm SEM. Significance of arthritic vs control differences indicated by asterisks. ${ }^{*} p \leq 0.05 ;{ }^{* * *} p \leq$ 0.001 (Student's 2-tailed $t$ test). 
a. tail-heat

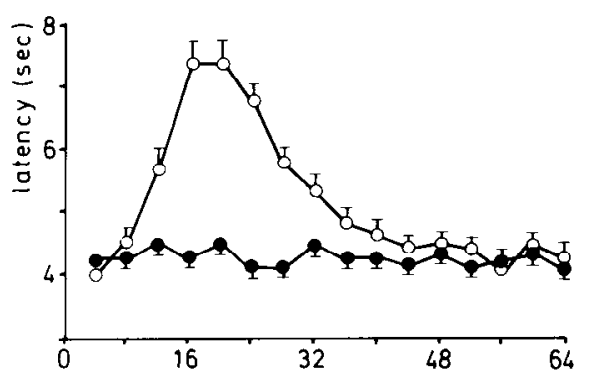

c. b. hind-paw-pressure

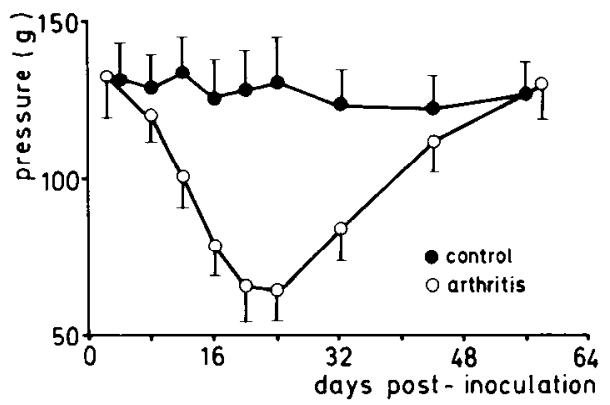

Figure 2. The influence of chronic arthritis upon the response to various nociceptive stimuli in the rat. $a$ and $b$, Time course over the entire period of study for the tail-flick response to heat and the paw withdrawal response to pressure. Control, $n=15$; arthritis $\mathrm{c}$, $n=18$. Means \pm SEM. At each time point from day 12 to 32 in each test, arthritic values differ significantly from corresponding control valucs $(p \leq 0.01$ on each day; Student's 2-tailed $t$ test). $c$, Nociceptive thresholds in each of the tests used are shown at $21 \mathrm{~d}$ postinoculation. $C$ (control), $n=15 ; A$ (arthritis), $n=18$; means \pm SEM. Asterisks indicate significance of arthritic vs control differences. ${ }^{*} p \leq 0.05 ;{ }^{* * *} p \leq 0.001$ (Student's 2-tailed $t$ test).
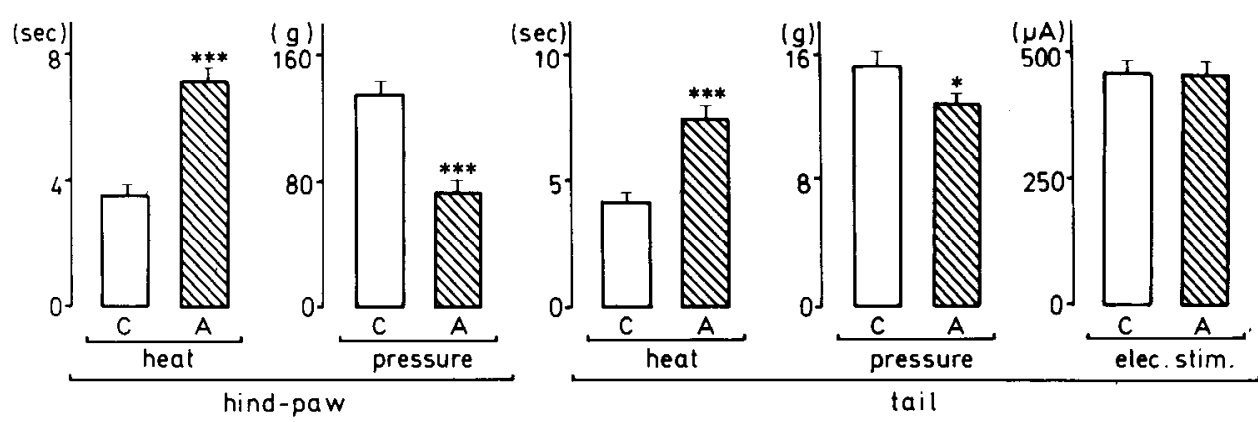

and water intake was disrupted is clearly revealed in the pronounced reduction in the ratio of dark- to light-phase food and water intake depicted in Figure 1. A modification of the rhythmicity of Tc was also seen (Fig. 1), with dark- and light-phase $\mathrm{Tc}$ in arthritic rats being, respectively, lower and higher than in control animals. This change in diurnal rhythmicity is most clearly expressed in the difference between dark-and light-phase core temperature shown by arthritic animals (Fig. 1).

\section{Nociceptive thresholds in arthritic rats}

The nociceptive thresholds of arthritic rats $21 \mathrm{~d}$ postinoculation (at the time of peak arthritis) are illustrated in Figure 2; the time course of alterations in nociceptive thresholds for 2 of the tests is also displayed. An identical time course was seen with the other tests. Alterations in threshold commenced parallel with the onset of symptoms, rapidly peaked at 3 weeks, and gradually disappeared in parallel with recovery from arthritis.

It is evident from Figure 2 that the nature of the noxious stimulus is a critical variable. Characteristic of arthritic rats is the pronounced reduction in thresholds for withdrawal of the hindpaw from noxious pressure. In contrast, there was a marked elevation in the latency to withdrawal of the paws from noxious heat. A similar pattern of changes was seen for the tail, with a (slight) reduction and increase in thresholds to pressure and heat, respectively. A Wilcoxon matched-pairs analysis revealed that the difference between the magnitude of the changes scen for the paw, compared with the tail, was significant (pressure: $p \leq$ 0.001 ; heat: $p \leq 0.01$ ). The greater magnitude of changes in threshold observed in the paw, compared with the tail, corresponds to the fact that the pathological tissue changes seen were more pronounced in the hindpaw than in the tail. As distinguished from reactions to pressure and heat, there was no significant alteration in the nociceptive threshold for electrical stimulation of the tail (Fig. 2).

It should be emphasized that the distinctions among pressure, heat, and electrical stimulation do not reflect the methodology employed: We have established that the changes were not due to repeated testing, in that as-yet-untested rats, upon examination 3 weeks postinoculation, revealed a pattern of changes identical to those shown in Figure 2. Further, the changes did not reflect the order of testing, since rats in which only a single test was employed showed the same pattern of changes.

\section{Influence of opioid antagonists upon nociceptive thresholds}

None of the opioid antagonists employed significantly modified the response of control rats to noxious heat or pressure applied to the paw or tail (not shown). Further, in arthritic rats, none of the antagonists modified the response of the paw or tail to heat (Fig. 3, Table 2). Neither naloxone nor ICI-154, 159, a preferential $\delta$-antagonist, modified the response to pressure in arthritic rats. However, MR 2266, which has greater activity than naloxone or ICI-154, 159 at $\kappa$-receptors, significantly decreased the response thresholds of both the paw (Fig. 3) and tail (Table 2) to noxious pressure-i.e., it potentiated this "pressure hyperalgesia." This was a stereospecific effect, since its inactive stereoisomer, MR 2267, was ineffective.

From Table 3, it can be seen that inoculation with yeast of the paw of naive, nonarthritic rats led to the rapid development of a reduced response threshold to noxious pressure. This hyperalgesia was not, however, potentiated by MR 2266, nor was it significantly affected by $5 \mathrm{mg} / \mathrm{kg}$ naloxone (not shown).

\section{Influence of morphine and $U-50,488 H$ upon nociceptive thresholds}

In each of the nociceptive tests employed, a potentiation of the antinociceptive action of the $\mu$-agonist, morphine, was seen (Fig. 4). Thus, as reflected in the shift of dose-response curves to the left, the antinociceptive action of morphine against both noxious heat and pressure is facilitated in arthritic rats. The dose-response curves were analyzed by ANOVA. The findings were as follows: tail flick, heat: drug effect, $F(2,31)=36.77, p<0.001$; arthritis effect, $F(1,31)=6.26, p=0.011$; interaction factor, 
PRESSURE

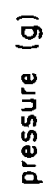

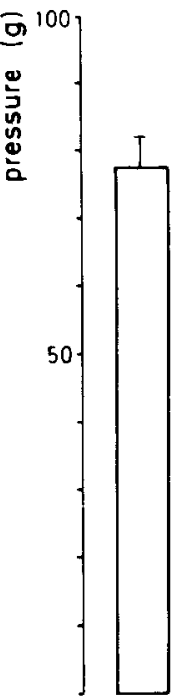

SAL NLX

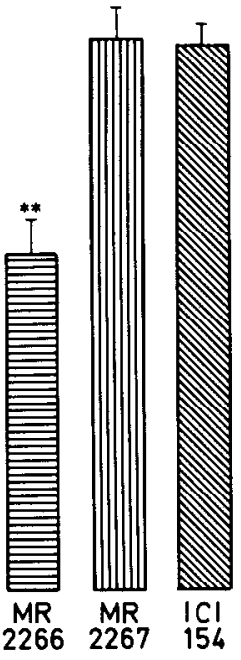

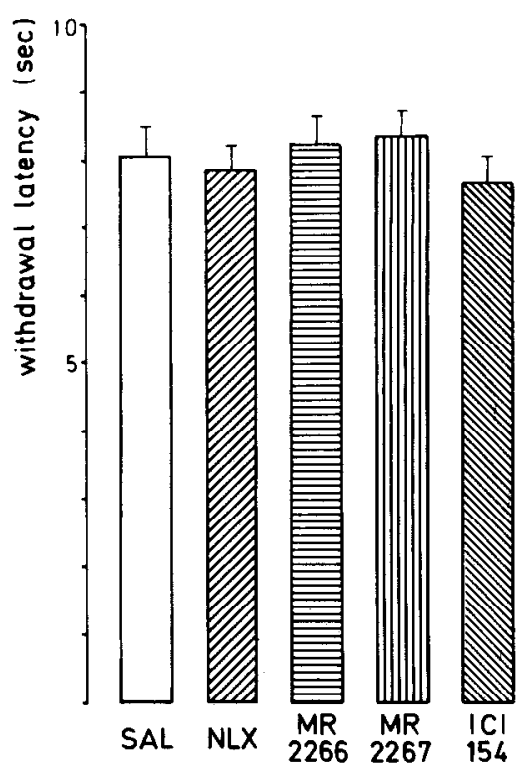

Figure 3. Influence of various opioid receptor antagonists on the withdrawal response of the paw to noxious pressure or heat in arthritic rats. $N L X$, naloxone; $S A L$, saline. Means \pm SEM. $n=8$ per column. Significance of arthritis + MR 2266 vs arthritis + saline values is shown. ${ }^{* *} p \leq 0.01$ (Student's 2 -tailed $t$ test).
$F(2,31)^{\prime}=4.71, p=0.018$. That the interaction factor is statistically significant reflects the alteration in the shape of the dose-response curve in arthritic rats, with the flattening at the highest dose being "artifactual" in that all rats had reached "cutoff." Tail withdrawal, pressure: drug effect, $F(2,26)=35.87$, $p<0.001$; arthritis effect, $F(1,26)=20.77, p<0.001$; interaction factor, $F(2,26)=1.76, p>0.05$. Paw withdrawal, pressure: drug effect, $F(2,26)=11.06, p<0.001$; arthritis effect, $F(1,26)=28.19, p<0.001$; interaction factor, $F(2,26)=3.02$, $p>0.05$. ANOVA of the time-effect curves in Figure 4 'revealed a significant effect of time and arthritis, but no interaction (ANOVA not shown). To summarize: In arthritic rats the intensity of morphine antinociception is enhanced, but its dose-response relationship and time course are not modified.

It is apparent from Figure 5 that arthritic rats respond quite differently to U-50,488H, a selective agonist at $\kappa$-receptors (Vonvoigtlander et al., 1983; Wehemeyer and Mack, 1985), whose antinociceptive effect was attenuated. This attenuation was most pronounced in the paw pressure and tail pressure tests and less powerful in the tail-flick test to heat. The results of these tests were analyzed by ANOVA. Tail-flick, heat: drug effect, $F(2$, $38)=22.78, p<0.001$; arthritis effect, $F(1,38)=4.81, p=$ 0.035 ; interaction factor, $F(2,38)=0.28, p>0.05$. Tail, withdrawal, pressure: drug effect, $F(2,45)=9.82 ; p<0.001$; arthritis effect, $F(1,45)=26.16, p<0.001$; interaction factor, $F(2,45)=$ $1.29, p>0.05$. Paw withdrawal, pressure: drug effect, $F(2,44)=$
20.26, $p<0.001 ;$ arthritis effect, $F(1,44)=31.63, p<0.001$ interaction factor, $F(2,44)=1.76, p>0.05$. ANOVA of timeeffect curves in Figure 5 revealed a significant effect of time and arthritis, but no interaction (ANOVA not shown). Thus, in arthritic rats, the intensity of $\mathrm{U}-50,488 \mathrm{H}$ antinociception is reduced, but the dose-respanse relationship and time course are not modified.

\section{Influence of morphine and $U-50,488 H$ upon endocrine secretion}

In a previous study (Millan et al., 1986a), we found basal levels of ir $\beta$-EP in the systemic circulation of untreated arthritic rats to be significantly higher in arthritic, compared with control, rats. In this study (Fig. 6), a tendency for an increase in ir $\beta$-EP levels in saline-treated animals was seen, but this was not statistically significant, owing to higher variability. This difference may also rclate to the "stress" of saline injections in this study. Morphine induced a minor but significant rise in plasma levels of ir $\beta$-EP in both arthritic and control rats; there was no significant difference between them as regards their response. ANOVA: drug effect, $F(1,37)=8.39, p=0.006$; arthritis effect, $F(1,37)=0.28, p>0.05$; interaction factor, $F(1,37)=0.29$, $p>0.05$, U-50,488 $\mathrm{H}$ also provoked a rise in plasma ir $\beta$-EP, the magnitude of which was significantly different (greater) in arthritic rats compared with control animals. ANOVA: for effect of drug, $F(1,34)=14.9, p<0.001$; for effect of arthritis, $F(1$,

Table 2. Influence of naloxone or MR 2266 upon nociceptive thresholds of arthritic rats

\begin{tabular}{|c|c|c|c|c|c|c|}
\hline & \multicolumn{3}{|l|}{ Tail pressure (gm) } & \multicolumn{3}{|l|}{ Tail heat (sec) } \\
\hline & Saline & Naloxone & MR 2266 & Saline & Naloxone & MS 2266 \\
\hline Control & $15.58 \pm 0.86$ & $13.99 \pm 0.71(8)$ & $14.43 \pm 0.86(5)$ & $4.26 \pm 0.27(11)$ & $3.94 \pm 0.21(8)$ & $4.02 \pm 0.29(5)$ \\
\hline Arthritis & $12.42 \pm 0.81(17)$ & $11.04 \pm 0.80(8)$ & $* * 8.24 \pm 0.84(10)$ & $6.76 \pm 0.48^{\prime}(17)$ & $6.61 \pm 0.41(8)$ & $7.47 \pm 0.34(10)$ \\
\hline
\end{tabular}

Means \pm SEM; $n$ is in parentheses. Significance of arthritis + MR 2266 vs arthritic + saline values is indicated by asterisks; ${ }^{* *} p \leq 0.01$ (Student's 2 -tailed $t$ test). All arthritic values are significantly different from corresponding control values. 
Table 3. Iack of influence of MR 2266 upon yeast-induced hyperalgesia to noxious pressure in naive, nonarthritic rats

\begin{tabular}{llll} 
& Pre-yeast & $1 \mathrm{hr}$ post-yeast & $\begin{array}{l}1 \mathrm{hr} \text { post-yeast }+ \\
\text { saline }\end{array}$ \\
\hline Saline (8) & $121.12 \pm 7.21$ & $* * 75.41 \pm 4.50$ & $* * 74.46 \pm 6.71$ \\
& Pre-yeast & $1 \mathrm{hr}$ post-yeast & $\begin{array}{l}1 \mathrm{hr} \text { post-yeast }+ \\
\text { MR 2266 }\end{array}$ \\
\hline MR 2266 (8) & $114.29 \pm 7.06$ & $* * 77.16 \pm 3.94$ & $* * 83.66 \pm 3.72$
\end{tabular}

Means \pm SEM of paw pressure thresholds (gm); $n$ is in parentheses. Significance of post-yeast vs pre-yeast values is indicated by asterisks; ${ }^{* *} p \leq 0.01$ (Wilcoxon matched-pairs test). No significant difference between yeast + saline and yeast + MR 2266 values (Student's 2-tailed $t$ test).

$34)=5.25, p=0.028$; interaction factor, $F(1,34)=4.83, p=$ 0.035 .

As shown in Table 4, in arthritic rats the anterior lobe concentrations of ir $\beta$-EP were significantly greater than in control animals. In conjunction with the pronounced rise in circulating ir $\beta$-EP elicited by $\mathrm{U}-50,488 \mathrm{H}$ in arthritic rats, a significant depletion in anterior (but not neurointermediate) lobe pools of ir $\beta$-EP was detected (Table 4). Thus, the anterior lobe may be the source of the elevated plasma levels of ir $\beta$-EP manifested by arthritic rats treated with $\mathrm{U}-50,488 \mathrm{H}$.

There was no significant difference between saline-treated arthritic and control rats as regards plasma levels of ir PRL. In view of the stress of handling, to which PRL is exquisitely sensitive, these should not be regarded as basal levels. We have measured these levels in an independent group that displayed a strong tendency toward a decrease which did not attain significance owing to the (typically) high scattering seen in basal values (mean \pm SEM; control: $n=9,8.70 \pm 2.90$; arthritis: $n=15$, $4.69 \pm 0.90 ; p>0.05$; Student's 2-tailed $t$ test). Morphine induced a dose-dependent elevation in these values in control and arthritic animals; the magnitudes did not differ between the respective groups. ANOVA: drug effect, $F(2,70)=121.32, p<$ 0.001 ; arthritis effect, $F(1,70)=0.68, p>0.05$; for interaction factor, $F(2,70)=1.9, p>0.05$. U-50,488H similarly induced a marked increase in circulating ir PRL of a comparable magnitude in control and arthritic rats. ANOVA: for drug, $F(1,36)=50.6$, $p<0.001$; for arthritis, $F(1,36)=1.73, p>0.05$; interaction factor, $F(1,36)=0.44, p>0.05)$.

Since the anterior pituitary is composed predominantly of lactotrophs (as opposed to the small fraction of corticotrophs), it is most meaningful to express ir PRL levels in terms of content. Neither morphine nor U-50,488H significantly modified anterior lobe content (or concentrations) of ir PRL (not shown). However, as shown in Table 5, the anterior lobe of arthritic rats showed a slight decrease in weight, with a significant decrease in the content of ir PRL.

Correlation analyses showed that the increases in plasma ir $\beta$-EP and ir PRL in response to morphine or $\mathrm{U}-50,488 \mathrm{H}$ were not significantly mutually correlated. Pearson's product-moment correlation coefficient: morphine, $r=0.30, p>0.05$; $\mathrm{U}-50,488 \mathrm{H}, r=-0.02, p>0.05$.

\section{Discussion}

Characteristics of arthritic rats

Arthritic rats displayed pronounced hypodipsia, hypophagia, and loss of body weight. It is likely that the discomfort involved in obtaining food was a contributory factor in these changes. However, food intake was higher in the light phase, and rats
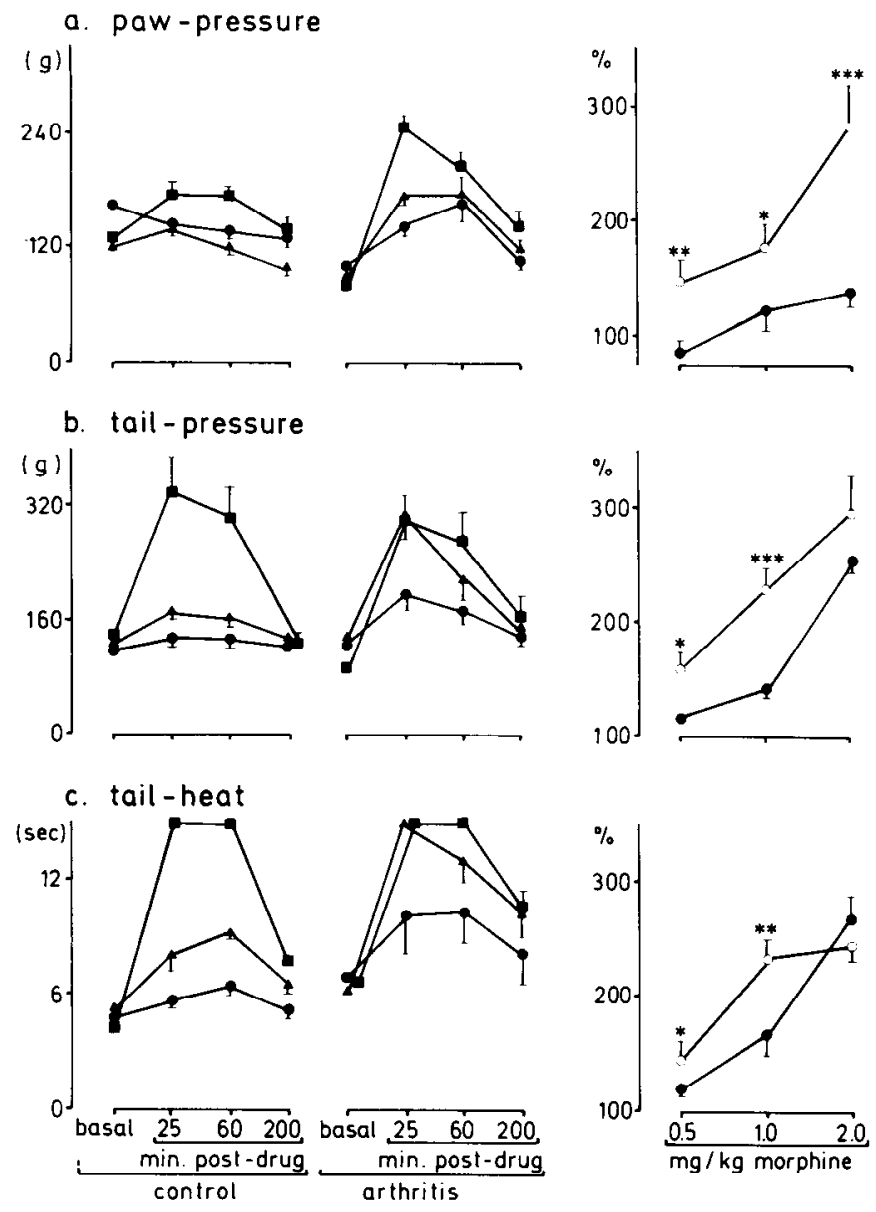

Figure 4. Influence of acutely applied morphine upon nociceptive thresholds of arthritic rats. Left-hand side shows the time course for the effect of morphine. For both control and arthritis, symbols are as follows: $0,0 \mathrm{mg} / \mathrm{kg}$, s.c.; $\Delta, 1.0 \mathrm{mg} / \mathrm{kg}$, s.c.; and $\mathbf{0}, 2.0 \mathrm{mg} / \mathrm{kg}$, s.c. Mcans \pm SEM. Right-hand side depicts the dose-response relationship. Control, closed circles; arthritis, open circles. Antinociception is expressed as a percentage of basal, preinjection values (= 100\%). Means \pm SEM. Significance of arthritic vs control values indicated by asterisks. ${ }^{*} p \leq 0.05$; ${ }^{* *} p \leq 0.01 ;{ }^{* * *} p \leq 0.001$ (Student's 2-tailed $t$ test). For each dose in control and arthritic rats, $n \geq 6$. Basal values are as follows. Paw pressure: control, $138.33 \pm 7.52$ vs arthritis, $88.67 \pm 4.28 ; p \leq 0.001$. Tail pressure: control, $128.00 \pm 9.6$ vs arthritis, $108.31 \pm 5.61$; NS. Tail heat: control, $4.98 \pm 0.20$ vs arthritis, $6.54 \pm 0.31, p<0.001$ ( $p$ values calculated by Student's 2-tailed $t$ test.)

subjected to recurrent footshock (Höllt et al., 1986) also display such changes, suggesting that other processes may be involved. In this regard, corticotropin-releasing factor deserves consideration. This is a potent anorexic agent (Morley et al., 1985) and manifests an increased activity in rats with chronic arthritis or exposed to recurrent footshock (Höllt et al., 1986). Indeed, a role for this peptide in certain chronic stress-related conditions of reduced appetite in humans has been proposed (Donohoe, 1984; Morley et al., 1985). Irrespective of the neurochemical mechanism, the data exemplify the complexity of this arthritic model of chronic pain and provide an additional illustration of the parallels between this condition and that of chronic pain in humans, which is typically associated with a suppression of appetite and a loss of body weight. A disruption of daily rhythms is also a familiar corollary of chronic pain in humans and, analogously, arthritic rats revealed an alteration in the diurnal scheduling of food and water intake. A similar change was seen for 

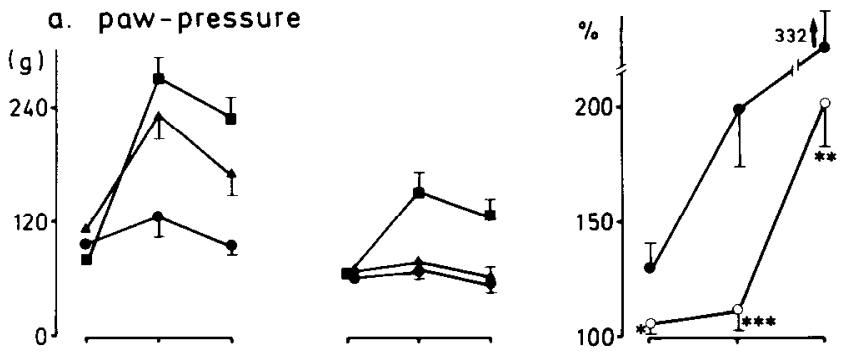

b. tail-pressure
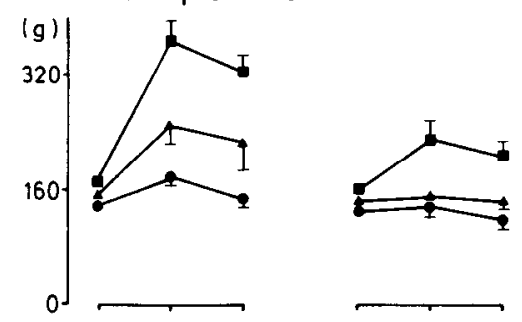

c. tail-heat
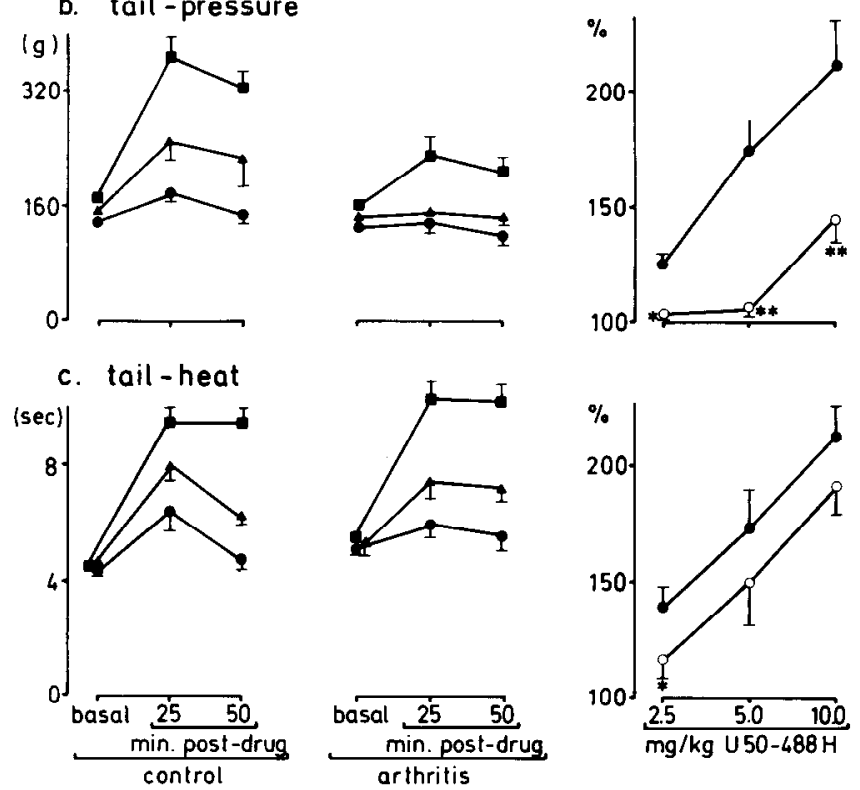

Figure 5. Influence of acutely applied $\mathrm{U}-50,488 \mathrm{H}$ on nociceptive thresholds of arthritic rats. Left-hand side shows the time course for the effect of U-50,488H. For both control and arthritis, symbols are as follows: $\bullet, 2.5 \mathrm{mg} / \mathrm{kg}$, s.c.; $\Delta, 5.0 \mathrm{mg} / \mathrm{kg}$, s.c.; and $\square, 10.0 \mathrm{mg} / \mathrm{kg}$, s.c. Means \pm SEM. Right-hand side depicts the dose-response relationship. Control, closed circles; arthritis, open circles. Antinociception is expressed as a percentage of basal preinjection values $(=100 \%)$. Means \pm SEM. Significance of arthritis vs control values indicated by asterisks. ${ }^{*} p \leq 0.05 ;{ }^{* *} p \leq 0.01 ;{ }^{* * *} p \leq 0.001$ (Student's 2-tailed $t$ test). For each dose in control and arthritic rats, $n \geq 6$. Basal values are as follows. Paw pressure: control, $105.06 \pm 6.81$ vs arthritis, $65.06 \pm 3.93 ; p \leq$ 0.001 . Tail pressure: control, $157.26 \pm 5.88$ vs arthritis, $139.00 \pm 4.76$; $p \leq 0.05$. Tail heat: control, $4.61 \pm 0.13$ vs arthritis, $5.71 \pm 0.19 ; p<$ 0.002 ( $p$ values calculated by Student's 2-tailed $t$ test.)

core temperature, possibly secondary to the shift in food intake since patterns of food intake can operate as an entrainer of diurnal rhythms of core temperature (Boulos and Terman, 1980). Arthritic rats revealed pronounced alterations in their response
Table 5. Anterior lobe weight, concentration, and content of immunoreactive prolactin in arthritic rats

\begin{tabular}{lrrl} 
& \multicolumn{3}{l}{ Immunorcactive prolactin } \\
\cline { 2 - 4 } & \multicolumn{1}{l}{$\begin{array}{l}\text { Weight } \\
(\mathrm{gm})\end{array}$} & $\begin{array}{l}\text { Content } \\
(\mathrm{mg} / \mathrm{lobe})\end{array}$ & $\begin{array}{l}\text { Concentration } \\
(\mu \mathrm{g} / \mathrm{mg})\end{array}$ \\
\hline Control (14) & $8.38 \pm 0.30$ & $149.61 \pm 5.79$ & $17.85 \pm 0.80$ \\
Arthritis (19) & $* 7.46 \pm 0.30$ & $* * 123.64 \pm 6.86$ & $16.56 \pm 1.05$
\end{tabular}

Means \pm SEM. Significance of arthritic vs saline values is indicated. ${ }^{*} p \leq 0.05$ ${ }^{* *} p \leq 0.01$ (Student's 2-tailed $t$ test)

to various types of noxious stimuli, the time course paralleling that of arthritic pathology (Fig. 2). There was an unequivocal distinction in the changes in responses to heat, pressure, and electrical stimulation. Since heat and pressure were shifted in opposite directions, it is improbable that the changes reflected a generalized interference with motor systems controlling nociceptive reflexes. Further, electrophysiological studies have shown parallel changes in the properties of neurons in the thalamus and spinal cord (Menetrey and Besson, 1982; Gautron and Guilbaud, 1983) (see below). The difference in heat vs pressure vs electrical stimulation exemplifies the important point that an animal cannot be simply classified as "analgesic" or "hyperalgesic." It is imperative that the quality of the noxious stimulus be specified. A hyperresponsiveness to noxious pressure is a characteristic feature of inflamed tissue (Fig. 1). This exaggerated sensitivity probably relates to the sensitization of peripheral fibers by algogenic substances such as prostaglandins and substance $P$, whose levels are elevated in the sciatic nerve of arthritic rats (Colpaert et al., 1983). Electrophysiological studies of the dorsal horn and ventrobasal thalamus have provided a parallel pattern of data, with neurons therein showing a reduced reaction threshold (and an amplified response) to pressure applied to the limbs (Menetrey and Besson, 1982; Gautron and Guilbaud, 1983).

Moreover, in these studies, neurons in the above-mentioned regions revealed an increase in their response threshold to heat that was in accordance with our behavioral observations. There may have been a peripheral component underlying the reduced response to heat; for example, the rise in temperature of the inflamed tissue may have produced an (upward) resetting of the response threshold, nociceptors with higher threshold may have been recruited, or the skin may have provided a physical screen. However, that there was a central mechanism involved was indicated by the following: (1) Chronic treatment of arthritic rats with opioid agonists prevented the rise in thresholds to heat without affecting limb pathology (Colpaert, 1979); (2) the thresh-

Table 4. Influence upon pituitary levels of immunoreactive $\beta$-endorphin of acute treatment with U-50,448H (10 mg/kg, $\mathrm{s.c}$.) or morphine (4 mg/ kg, s.c.)

\begin{tabular}{|c|c|c|c|c|c|c|}
\hline & \multicolumn{3}{|l|}{ Anterior lobe } & \multicolumn{3}{|c|}{ Neurointermediate lobe } \\
\hline & Saline & $\mathrm{U}-50,488 \mathrm{H}$ & Morphine & Saline & $\mathrm{U}-50,488 \mathrm{H}$ & Morphine \\
\hline Control & $50.31 \pm 3.31(7)$ & $45.58 \pm 7.09(4)$ & $48.41 \pm 3.08(6)$ & $600.46 \pm 45.08(7)$ & $639.38 \pm 91.21$ & $664.22 \pm 84.17(6)$ \\
\hline Arthritis & $* * 77.81 \pm 5.39(14)$ & $* 62.38 \pm 2.76(5)$ & NE & $558.50 \pm 38.18(14)$ & $603.21 \pm 106.08(5)$ & $\mathrm{NE}$ \\
\hline
\end{tabular}

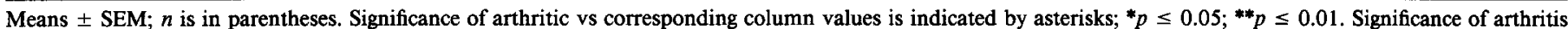
$+\mathrm{U}-50,488 \mathrm{H}$ vs arthritis + saline values indicated by dark type: $p \leq 0.02$ (Student's 2 -tailed $t$ test). NE, not evaluated. 
a. immunoreactive $\beta$-endorphin

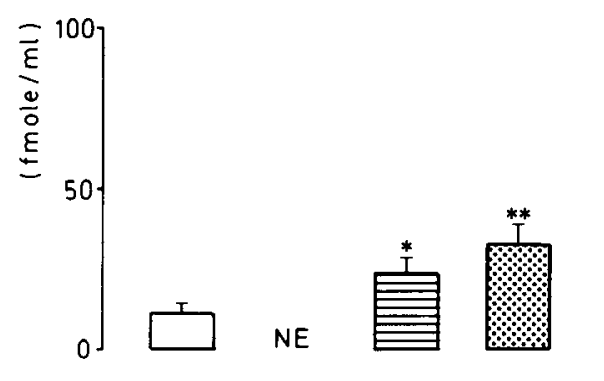

b. immunoreactive prolactin

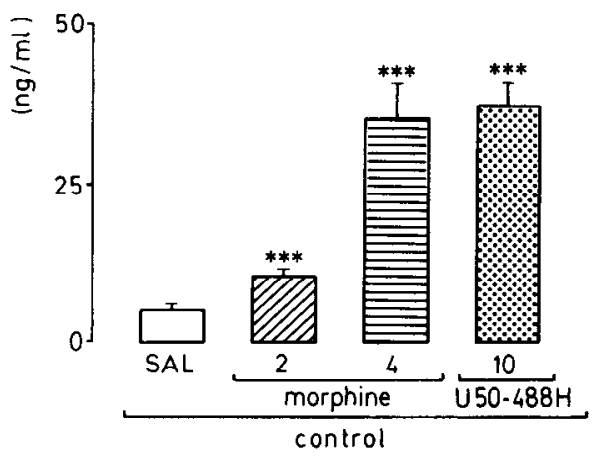

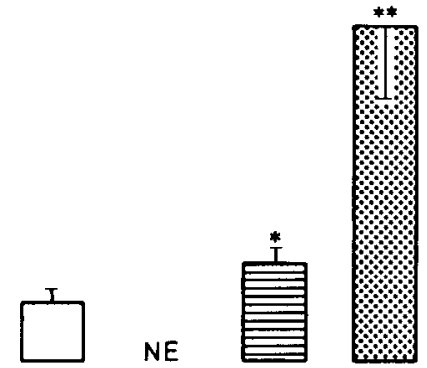

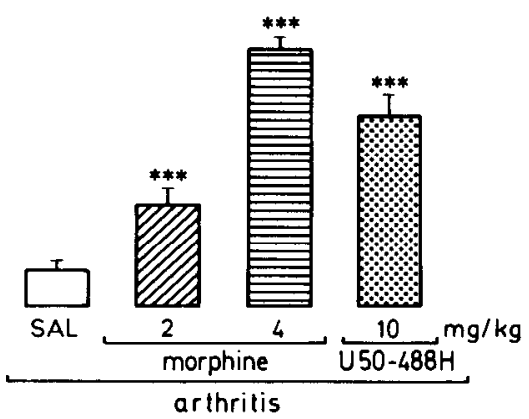

Figure 6. Influence of morphine or U-50,488H on levels of immunoreactive $\beta$-endorphin (ir $\beta$-EP) and immunoreactive prolactin (ir PRL) in the systemic plasma of arthritic rats. $N E$, not evaluated; $S A L$, saline. Means \pm SEM. $n=8$ per column. Significance of morphine or $\mathrm{U}-50,488 \mathrm{H}$ vs SAL values is indicated by asterisks. ${ }^{*} p \leq 0.05 ;{ }^{* *} p \leq$ $0.01 ;{ }^{* * *} p \leq 0.001$ (Student's 2-tailed $t$ test). old to heat was elevated at the tip of the tail, where pathology is usually absent; (3) chronic mechanical stimulation of the limbs likewise elevated thresholds to noxious heat applied to the tail (Colpaert et al., 1980).

\section{Endogenous and exogenous opioid control of nociception in arthritic rats}

Since none of the antagonists affected the elevated thresholds to noxious heat, it is very unlikely that endogenous opioids mediate this rise. Naloxone and ICI-154,129, a preferential $\delta$-antagonist (Shaw et al., 1982; Priestley et al., 1985), likewise failed to modify the withdrawal response of the paw or tail to noxious pressure. A hyperalgesic effect of naloxone has, in contrast, been reported with regard to the vocalization response to pressure or electrical stimulation in arthritic rats (Oliveras et al., 1979; Kayser and Guilbaud, 1981). This difference can be explained by the fact that vocalization is a fundamentally different response in that it is suprasegmentally integrated and reflects the affective/emotional dimension of nociception, as compared with the spinally coordinated motor withdrawal reflex. Interestingly, with extremely low doses of naloxone $(10 \mu \mathrm{g} /$ $\mathrm{kg}$ ), analgesia has been reported in arthritic rats (Kayser and Guilbaud, 1981). A comparable pattern of data has been seen regarding the withdrawal reflex to pressure in cases of acute inflammation, with high doses of naloxone being inactive and low doses causing analgcsia (scc Results; Chipkin ct al., 1982; Rios and Jacob, 1984). As is explained elsewhere (Millan, 1986), this paradoxical analgesia appears to be due to a peripheral action of naloxone upon extra-CNS opioid receptors with poorly defined characteristics, probably located within the paw itself.

MR 2266, which possesses a much greater ability to block $\kappa$-receptors than does naloxone (Magnan et al., 1982; Vonvoigtlander et al., 1983), decreased thresholds for withdrawal of the paw to noxious pressure; that is, it potentiated the hyperalgesia. This was a highly specific and selective action, in that (1) the opioid-inactive stereoisomer, MR 2267, was ineffective, (2) MR
2266 did not affect the response to noxious heat, (3) MR 2266 was inactive in control rats, and (4) MR 2266 proved inactive in rats with acute inflammation. The most reasonable explanation is that MR 2266 blocks the activity of DYN at spinally localized $\kappa$-receptors involved in the modulation of the reflex withdrawal response to noxious pressure under chronic arthritic pain. Such a possibility finds support in our parallel finding of a pronounced rise in levels of ir DYN in the spinal cord (Table 1), which correlates with the intensity and time course of the hyperalgesia (Millan et al., 1985). Further, arthritic rats show a reduction in spinal cord $\kappa$-receptors (Millan et al., 1986a), where DYN is believed to act (Wüster et al., 1981; James et al., 1984), probably owing to an enhanced activity of DYN that leads to their down-regulation. This is also reflected in the loss of antinociceptive potency of the $\kappa$-ligand, $U-50,488 \mathrm{H}$. Indeed, a role for spinal DYN via a $\kappa$-receptor in arthritic rats would be consistent with data indicating that $\kappa$-agonists express their antinociceptive effects primarily at the spinal level (Przewlocki et al., 1983; Basbaum and Fields, 1984; Han et al., 1984; Millan, 1986).

Evidently the biochemical and pharmacological data are mutually complementary. It should be borne in mind, however, that we are concerned with a spinal motor reflex response to an acute noxious stimulus, and it is only in this sense that one is justified in speaking in terms of a control of chronic pain. Nevertheless, spinal DYN, by blocking the flow of noxious information to higher centers, might be able to modify the affective component of pain; moreover, recently it was claimed that intrathecal DYN relieved intractable chronic pain in man (Wen et al., 1985).

In distinction to the attenuation seen in the antinociceptive potency of $\mathrm{U}-50,488 \mathrm{H}$, a pronounced enhancement in the antinociceptive action of the $\mu$-agonist, morphine was seen in arthritic rats (Fig. 4; Kayser and Guilbaud, 1983, 1985). This contrast, and the lack of change in the time course (see Results), counters the argument that pharmacokinetic factors could account for these changes. A further consideration is the lack of 
comparable changes influenced by these drugs in the endocrine secretion of the pituitary (see below). The reduction in the antinociceptive efficacy of $U-50,488 \mathrm{H}$ can be related to the loss of $\kappa$-receptors in the lumbosacral spinal cord (Millan et al., 1986a) and a cross-tolerance to endogenous DYN. With regard to the augmented potency of morphine, the relative rise in spinal $\mu$-receptors (Millan, 1986a) may be relevant, but it is likely that a postreceptor mechanism is primarily responsible. Although there are conflicting data, 5-HT appears to play at least a partial role in the expression of the antinociceptive actions of systemically applied morphine (Messing and Lyttle, 1977; Mohrland and Gebhart, 1980; Berge et al., 1983; Kuraishi et al., 1983; Basbaum and Fields, 1984; Auerbach et al., 1985). Arthritic rats manifest an increase in the activity of brain and spinal pools of 5-HT and an enhanced ability for morphine to activate these pools (Weil-Fugazza et al., 1979). Further, an increase in the activity of serotoninergic networks may underlie the potentiated antinociceptive action of morphine induced by acute stress (Kelly and Franklin, 1984). In analogy to arthritis, other models of chronic pain (footshock or mechanical stimulation) evoke an increased antinociceptive response to morphine (Lewis et al., 1981; Appelbaum and Holtzman, 1984; Sherman et al., 1984; Williams et al., 1984; Girardot and Holloway, 1985). It has been contended that this may reflect classical conditioning; that is, cues associated with exposure to stress summate with morphine to produce an enhanced antinociception. Though the present study did not evaluate the possibility of systematic conditioning, it would not appear to be likely in the case of chronic arthritis, in which rats are inoculated only once. Thus, the facilitation seen in arthritic rats may not reflect conditioning.

Many studies have examined the pharmacological spectrum of activity of $\mu$-compared with $\kappa$-agonists in the modulation of nociception. The present data reveal that their activity can be differentially modified by physiological stimuli. Evidently, under these conditions of chronic pain, they.can show strikingly different functional changes and apparently fulfill very different physiological roles.

\section{Opioid control of endocrine secretion in arthritic rats}

Both acute and chronic exposure to stress can modify the secretion of ir $\beta$-EP into the systemic circulation. Indeed, an accelerated hypophyseal release of ir $\beta$-EP may be regarded as a definitive response to acute stress (Guilleman et al., 1977; Millan, 1981; Mueller, 1981; Vermes et al., 1981; Akil et al., 1985; Millan and Herz, 1985). Further, many acute stressors that activate corticotrophs enhance the lactotrophic secretion of PRL (Du Ruisseau et al., 1979; Kawakami et al., 1979). In view of these similarities, it is of interest to compare the response of $\beta$-EP and PRL to chronic arthritic pain. The present data are in line with our previous observation (Millan et al., 1986a) of an enhanced activity of $\beta$-EP-synthesizing corticotrophs in chronic arthritis. By contrast, however, arthritic rats display a reduction in the anterior lobe content of ir PRL and in the levels of mRNA encoding PRL in the adenohypophysis, and a tendency for a fall in plasma ir PRL (Fig. 6, Table 5; Höllt et al., 1986). Further, we found that rats subjected to recurrent footshock showed a pronounced increase in the synthetic and secretory activity of anterior lobe corticotrophs, but not lactotrophs (Höllt et al., 1986). Moreover, chronic immobilization stress elicits a reduction in circulating ir PRL (Du Ruisseau et al., 1979; Lopez-Calderon and Tresguerres, 1981). Evidently, though they are activated together by acute stress, only the aug- mented activity of $\beta$-EP is maintained under chronic stress, whereas the activity of ir PRL may be the same as, or even reduced, compared with basal levels.

The secretion of both $\beta$-EP and PRL also possesses the common property of being subject to modulation by opioids. There is uncertainty about the receptor types involved. However, the current data are consistent with those of most authors in indicating that a $\mu$-receptor can modulate the release of each hormone (Millan and Herz, 1985; Krulich et al., 1986). Also, in line with recent work (Krulich et al., 1986) the use of U-50,488H provides strong evidence for the role of $\kappa$-receptors. Interestingly, arthritic rats showed an enhanced response of ir $\beta$-EP, but not ir PRL, to the $\kappa$-agonist, the levels of which did not correlate with each other in plasma. Possibly, this enhancement relates to the increase in the density of $\kappa$-receptors seen by autoradiography in discrete regions of the brain of arthritic rats, such as the periaqueductal gray, stimulation of which elicits the secretion of PRL (B. Morris and M. J. Millan, unpublished observations). Whether these points indicate that a different pool of $\kappa$-receptors, or a different postreceptor mechanism, is involved in $\kappa$-control of $\beta$-EP, compared with PRL, secretion remains to be seen.

Since the response of $\beta$-EP and PRL to morphine and $\mathrm{U}-50,488 \mathrm{H}$ was not reduced in arthritic rats, the data complement those of previous studies (Kawakami et al., 1979; Young and Akil, 1985) in indicating that the response of $\beta$-EP and PRL to releasing factors is not modified by chronic stress.

\section{Conclusion}

The present data illustrate the complexity of chronic arthritic pain in the rat. Of particular importance, the animals revealed contrasting responses, depending on the type of noxious stimulus applied. The data offer evidence for functionally significant changes in the activity of opioid systems controlling nociception and endocrine secretion during chronic pain. In this respect, a clcar distinction is apparent between $\mu$ - and $\kappa$-opioid receptors. Finally, parallel biochemical and pharmacological evidence for a role for spinal DYN, via $\kappa$-receptors, in the control of nociception under chronic pain is presented. These findings may be of direct clinical relevance for the management of long-term pain in man.

\section{References}

Akil, H., H. Shiomi, and J. Matthews (1985) Induction of the intermediate pituitary by press: Synthesis and release of a non-opioid form of $\beta$-endorphin. Science 227: 424-426.

Appelbaum, B. D., and P. F. Holtzman (1984) Characterization of stress-induced potentiation of opioid effects in the rat. J. Pharmacol. Exp. Ther. 231: 555-565.

Auerbach, S., C. Fornal, and B. L. Jacobs (1985) Response of serotonin-containing neurones in nucleus raphe magnus to morphine, noxious stimuli, and periaqueductal gray stimulation in freely-moving cats. Exp. Neurol. 88: 609-628.

Basbaum, A. I., and H. L. Fields (1984) Endogenous pain control systems: Brainstem spinal pathways and endorphin circuitry. Annu. Rev. Neurosci. 7: 309-338.

Benoist, J.-M., V. Kayser, M. Gautron, and G. Guilbaud (1983) Low dose of morphine strongly depresses responses of specific nociceptive neurones in the ventrobasal complex of the rat. Pain 15: 333-344.

Berge, O., K. Hole, and S. Ogren (1983) Attenuation of morphineinduced analgesia by $\mathrm{p}$-chlorophenyl-alanine and p-chloro-amphetamine: Test-dependent effects and evidence for brainstem 5-hydroxytryptamine involvement. Brain Res. 271: 51-64.

Boulos, Z., and M. Terman (1980) Food availability and daily biological rhythms. Ncurosci. Biobchav. Res. 4: 119-131.

Cesselin, F., S. Bourgoin, F. Artaud, and M. Hamon (1984) Basic and 
regulatory mechanisms of in vitro release of met-enkephalin from the dorsal zone of the rat spinal cord. J. Neurochem. 43: 763-773.

Cesselin, F., J. L. Montastruc, C. Gros, S. Bourgoin, and M. Hamon (1980) Met-enkephalin levels and opiate receptors in the spinal cord of chronic suffering rats. Brain Res. 191: 289-293.

Chipkin, R. E., W. Billard, L. C. Iorio, and A. Barnett (1982) Relationship of yeast-injection induced changes in brain met-enkephalin and analgesia. Peptides 3: 31-35.

Colpaert, F. C. (1979) Can chronic pain be suppressed despite purported tolerance to narcotic analgesia? Life Sci. 24: 1201-1210.

Colpaert, F. C., J. Donnerer, and F. Lembeck (1983) Effects of capsaicin on inflammation and on the substance $P$ content of nervous tissues in rats with adjuvant arthritis. Life Sci. 32: 1827-1834.

Colpaert, F. C., C. J. E. Niemegers, P. A. J. Jansern, and A. N. Maroli (1980) The effects of prior fentanyl administration and of pain on fentanyl analgesia: Tolerance to and enhancement of narcotic analgesia. J. Pharmacol. Exp. Ther. 213: 418-424.

Donohoe, T. P. (1984) Stress-induced anorexia: Implications for anorexia nervosa. Life Sci. 34: 203-218.

Du Ruisseau, P., Y. Taché, P. Brazeau, and R. Collu (1979) Effects of chronic immobilization stress on pituitary hormone secretion, on hypothalamic factor levels, and on pituitary responsiveness to LHRH and TRH in female rats. Neuroendocrinology 29: 90-99.

Faccini, E., M. Uzumaki, S. Govoni, C. Missale, P. F. Spano, V. Covelli, and M. Trabucchi (1984) Afferent fibres mediate the increase of met-enkephalin elicited in rat spinal cord by localized pain. Pain 18 : 25-31.

Gautron, M., and G. Guilbaud (1983) Somatic responses of ventrobasal thalamic neurones in polyarthritic rats. Brain Res. 237: 459471

Girardot, M.-N., and F. A. Holloway (1985) Chronic stress, aging and morphine analgesia: Chronic stress affects the reactivity to morphine in young but not in old rats. J. Pharmacol. Exp. Ther. 233: 535-553.

Guilbaud, G., J.-M. Benoist, M. Gautron, and V. Kayser (1982) Effects of systemic naloxone upon ventrobasal thalami neuronal responses in arthritic rats. Brain Res. 243: 59-66.

Guilleman, R., T. M. Vargo, J. Rossier, S. Minick, N. Ling, C. Rivier, W. Vale, and F. Bloom (1977) $\beta$-endorphin and adrenocorticotropin are secreted concomitantly by the pituitary gland. Science 197: 13671369.

Han, J. S., G. X. Xie, and A. Goldstein (1984) Analgesia induced by intrathecal injection of dynorphin B in the rat. Life Sci. 34: 15731579.

Hill, R. G., and C. M. Pepper (1979) The effect of morphine and metenkephalin on nociceptive neurones in the rat thalamus. Br. J. Pharmacol. 58: 459-460.

Höllt, V. (1983) Multiple endogenous opioid peptides. Trends Neurosci. 6: 24-26.

Höllt, V., R. Przewhocki, and A. Herz (1978) Radioimmunoassay of $\beta$-endorphin: Based and stimulated levels in extracted rat plasma. Naunyn Schmiedebergs Arch. Pharmacol. 303: 171-174.

Höllt, V., R. Przewłocki, I. Haarmann, O. F. X. Almeida, N. Kley, M. J. Millan, and A. Herz (1986) Stress-induced alterations in the levels of messenger RNA coding for proopiomelanocortin and prolactin in rat pituitary. Neuroendocrinology 43: 277-282.

Iadorola, M. J., H.-Y. T. Yang, and E. Costa (1985) Increase in the content of spinal cord dynorphin during an experimentally induced inflammation of the rat hind limbs. Fed. Proc. 44: 422.

James, I. F., W. Fischli, and A. Goldstein (1984) Opioid receptor selectivity of dynorphin gene products. J. Pharmacol. Exp. Ther. 22: 88-93.

Kawakami, M., T. Higuchi, and M. Matsuura (1979) Immobilization stress and prolactin secretion in male rats. Neuroendocrinology 29 . 262-269.

Kayser, V., and G. Guilbaud (1981) Dose-dependent analgesic and hyperalgesic effects of systemic naloxone in arthritic rats. Brain Res. 226: 344-348.

Kayser, V., and G. Guilbaud (1983) The analgesic effects of morphine, but not those of the enkephalinase inhibitor thiorphan are enhanced in arthritic rats. Brain Res. 267: 131-138.

Kayser, V., and G. Guilbaud (1985) Can tolerance to morphine be induced in arthritic rats. Brain Res. 334: 335-338.

Kelly, S. J., and K. B. J. Franklin (1984) Evidence that stress augments morphine analgesia by increasing brain tryptophan. Neurosci. Lett. 44: 305-310.
Krulich, L., J. I. Koenig, S. Conway, S. M. McCann, and M. A. Mayfield (1986) Opioid $\kappa$-receptors and the secretion of prolactin and growth hormone in the rat. Neuroendocrinology 42: 75-81

Kuraishi, Y., Y. Harada, S. Aratani, M. Satoh, and H. Tagaki (1983) Separate involvement of the spinal noradrenergic and serotinergic systems in morphine analgesia: The differences in mechanical and thermal algesic tests. Brain Res. 273: 245-252

Lewis, J. W., J. E. Sherman, and J. C. Liebeskind (1981) Opioid and non-opioid stress analgesia: Assessment of tolerance and cross-tolerance with morphine. J. Neurosci. 1: 358-363.

Lopez-Calderon, A., and J. A. F. Tresguerres (1981) The effects of chronic stress, ACTH or dexamethasone treatment on plasma prolactin (PRL) levels in the male rat. Acta Endocrinol. [Suppl. 243] 97 365.

Magnan, J., S. J. Paterson, A. Tavani, and H. W. Kosterlitz (1982) The binding spectrum of narcotic analgesic drugs with different agonist and antagonist properties. Naunyn Schmiedebergs Arch. Pharmacol. 319: 197-205.

Menetrey, D., and J. M. Besson (1982) Electrophysiological characteristics of dorsal horn cells in rats with cutaneous inflammation resulting from chronic arthritis. Pain 13: 343-364.

Messing, R. B., and L. D. Lyttle (1977) Serotonin-containing neurones: Their possible role in pain and analgesia. Pain 4: 1-21.

Millan, M. J. (1981) Stress and endogenous opioid peptides: A review. Mod. Probl. Pharmacopsychiatry 17: 49-67.

Millan, M. J. (1986) Multiple opioid systems and pain: A review. Pain (in press).

Millan, M. J., and A. Herz (1985) The endocrinology of the opioids. Int. Rev. Neurobiol. 26: 1-84.

Millan, M. J., R. Przewłocki, M. H. Jerlicz, C. Gramsch, and A. Herz (1981a) Stress-induced release of brain and pituitary $\beta$-endorphin: Major role of endorphins in generation of hyperthermia not analgesia. Brain Res. 208: 325-338.

Millan, M. J., Y. F. Tsang, R. Przewłocki, V. Höllt, and A. Herz (1981 b) The influence of foot-shock stress upon brain, pituitary, and spinal cord pools of immunoreactive dynorphin in the rat. Neurosci. Lett. 24: $75-79$

Millan, M. J., M. H. Millan, C. W. T. Pilcher, A. Czlonkowski, A. Herz, and F. C. Colpaert (1985) Spinal cord dynorphin may modulate nociception via a $k$-opioid receptor in chronic arthritic rats. Brain Res. 340: 156-159.

Millan, M. J., M. H. Millan, A. Członkowski, V. Höllt, C. W. T. Pilcher, A. Herz, and F. C. Colpaert (1986a) A model of chronic pain in the rat: Response of multiple opioid systems to adjuvant-induced arthritis. J. Neurosci. 6: 899-906.

Millan, M. J., M. H. Millan, A. Członkowski, C. W. T. Pilcher, V. Höllt, F. C. Colpaert, and A. Herz (1986b) Functional response of multiple opioid systems to chronic arthritic pain in the rat. Ann. NY Acad. Sci. 467: 182-193.

Mohrland, J. S., and G. F. Gebhart (1980) Effect of selective destruction of serotoninergic neurones in nucleus raphe magnus on morphine-induced antinociception. Life Sci. 27: 2627-2632.

Morley, J. E., T. J. Bartness, B. A. Gosnell, and A. S. Levine (1985) Peptidergic regulation of feeding. Int. Rev. Neurobiol. 27: 207-298.

Mueller, G. P. (1981) Beta-immunoreactivity in rat plasma: Variation in response to different physical stimuli. Life Sci. 29: 1169-1176.

Nyberg, F., T. L. Yaksh, and L. Terenius (1983) Opioid activity released from cat spinal cord by sciatic nerve stimulation. Life Sci. [Suppl. I] 33: 17-20.

Oliveras, J. L., J. Braxelle, A. M. Clot, and J.-M. Besson (1979) Effects of morphine and naloxone on painful reaction in normal and chronic suffering rats. Neurosci. Lett. [Suppl.] 3: 263.

Panerei, A. E., A. Martini, P. Sacerdote, and P. Mantegazza (1984) $\kappa$-Receptor antagonist reverses "non-opioid" stress-induced analgesia. Brain Res. 304: 153-156.

Priestley, T., M. J. Turnbull, and E. Wei (1985) In vivo evidence for the selectivity of ICI 154,129 for the delta opioid receptor. Neuropharmacology 24: 107-110.

Przewhocki, R., L. Stala, M. Greczek, G. T. Shearman, B. Przcwlocka, and A. Herz (1983) Analgesic effects of $\mu$-, and $\delta$ - and $\kappa$-opiate agonists and in particular, dynorphin, at the spinal level. Life Sci. [Suppl. I] 33: 649-652.

Rios, L., and J. J. C. Jacob (1984) Local inhibition of inflammatory pain by naloxone and its $N$-methyl quaternary analogue. Eur. J. Pharmacol. 96: 277-283. 
Robson, L. E., S. J. Paterson, and H. W. Kosterlitz (1983) Opiate receplors. In Handbook of Psychopharmacology, Vol. 14, S. D. Iversen, L. L. Iversen, and S. Snyder, eds., pp. 13-80, Plenum, New York.

Shaw, J. S., L. Miller, J. Turnbull, J. J. Gormley, and J. S. Morley (1982) Selective antagonists at the opioid delta receptor. Life Sci. 31: $1259-1262$.

Sherman, J. E., H. Strub, and J. W. Lewis (1984) Morphine analgesia: Enhancement of morphine-analgesia by shock-associated cues. Behav. Neurosci. 98: 293-309.

Spampinato, S., and S. Candeletti (1985) Characterization of dynorphin A-induced antinociception at spinal level. Eur. J. Pharmacol. 110: $21-30$

Terman, G. W., Y. Shavit, J.-W. Lewis, J.-T. Cannon, and J. C. Liebeskind (1984) Intrinsic mechanisms of pain inhibition: Activation by stress. Science 226: 1270-1272.

Vermes, I., F. Berrenbosch, F. J. H. Tilders, and P. G. Smelik (1981) Hypothalamic deafferentation in the rat appears to discriminate between the anterior lobe and intermediate lobe response to stress. Neurosci. Lett. 27: 89-93.

Vonvoigtlander, P. F., R. A. Lahti, and J. M. Luders (1983) U-50,488: A selective and structurally novel non-mu (kappa) opioid agonist. J. Pharmacol. Exp. Ther. 224: 7-12.

Watkins, L. R., and D. J. Mayer (1982) Organization of endogenous opiate and non-opiate pain control systems. Science 216: 1185-1192.

Weber, E., C. J. Evans, and J. D. Barchas (1982) Predominance of the amino-terminal octapeptide fragment of dynorphin in rat brain regions. Nature 299: 77-79.
Wehemeyer, J. A., and K. J. Mack (1985) Binding characteristics of kappa opioids in rat brain. A comparison of in vitro binding paradigms. Neuropharmacology 24: 111-115.

Weil-Fugazza, J., F. Godefroy, and J. M. Besson (1979) Changes in brain and spinal tryptophan and 5-hydroxy-indoleacetic-acid levels following morphine administration in normal and arthritic rats. Brain Res. 175: 291-301.

Wen, T. L., Z. D. Mehal, B. H. Ong, W. K. K. Ho, and D. Y. K. Wen (1985) Intrathecal administration of $\beta$-endorphin and dynorphin (113 ) in the treatment of intractable pain. Life Sci. 37: 1213-1220.

Williams, J. L., R. C. Drugan, and S. F. Maier (1984) Exposure to uncontrollable stress alters withdrawal from morphine. Behav. Neurosci. 98: 836-846.

Wüster, M., P. Rubini, and R. Schulz (1981) The preference of putative proenkephalins for different types of opiate receptors. Life Sci. 29: 1219-1227.

Yaksh, T. L., and R. P. Elde (1981) Factors governing the release of methionine-enkephalin-like immunoreactivity from mesencephalon and spinal cord of the cat in vivo. J. Neurophysiol. 4: 1056-1075.

Yaksh, T. L., L. Terenius, F. Nyberg, K. Jhamandas, and J.-J. Wang (1983) Studies on the release by somatic stimulation from rat and cat spinal cord of active materials which displace dihydromorphine in an opiate-binding assay. Brain Res. 268: 119-128.

Young, E. A., and H. Akil (1985) Corticotropin-releasing factor stimulation of adrenocorticotropin and $\beta$-endorphin release: Effects of acute and chronic stress. Endocrinology 117: 23-30. 